\section{REVIEW ARTICLE}

\title{
Autolysins of Bacillus subtilis: multiple enzymes with multiple functions
}

\author{
Thomas J. Smith, $\uparrow$ Steve A. Blackman $\ddagger$ and Simon J. Foster \\ Author for correspondence: Simon J. Foster. Tel: +44 114222 4411. Fax: +44 1142728697. \\ e-mail:s.foster@sheffield.ac.uk
}

Department of Molecular Biology and Biotechnology, University of Sheffield, Firth Court, Western Bank, Sheffield S10 2TN, UK

Keywords: Bacillus subtilis, peptidoglycan hydrolase, cell wall, vegetative growth, sporulation

\section{Overview}

Autolysins are bacteriolytic enzymes that digest the cellwall peptidoglycan of the bacteria that produce them (Shockman \& Höltje, 1994). Although potentially lethal, autolysins appear to be universal among bacteria that possess peptidoglycan. Peptidoglycan, the substrate of autolysins, is a polymer of amino sugars cross-linked by short peptides which forms a covalent matrix that surrounds the cytoplasmic membrane and constitutes the major skeletal component of the cell wall. It is critical in determining cell shape and preventing osmotic lysis under hypotonic conditions. Cell-wall peptidoglycan, whilst very strong, is also highly dynamic: the structure expands as the cell grows and is reshaped when it divides or differentiates. The possibility that autolysins are involved in selective removal of peptidoglycan has led to proposals that they are involved in numerous cellular processes including cell growth, cell-wall turnover, peptidoglycan maturation, cell division, separation, motility, chemotaxis, genetic competence, protein secretion, differentiation and pathogenicity (Foster, 1994; Blackman et al., 1998).

In this review, we consider Bacillus subtilis as a genetically amenable, nonpathogenic model system for investigating the roles of autolysins in the cell-wall metabolism of an endospore-forming Gram-positive bacterium. The various phases of the B. subtilis life cycle afford excellent opportunities to study all the above proposed functions of autolysins except those solely involved in pathogenicity.

Although autolysins associated with B. subtilis have been known for many years (Rogers et al., 1984), the study of their physiological roles has been hampered by

\footnotetext{
†Present address: Department of Biological Sciences, University of Warwick, Coventry CV4 7AL, UK.

$\ddagger$ Present address: School of Biological Sciences, Stopford Building, University of Manchester, Manchester M13 9PT, UK.
}

their great number and functional redundancy (Smith et al., 1996). However, by analysis of multiply inactivated mutants, study of peptidoglycan fine structure and, most recently, by sequencing of the entire $B$. subtilis genome (Kunst et al., 1997), it has become possible to define the roles played by individual autolysins in a number of important cellular processes. Here, we first seek to draw together enzymological and genome sequence information to define the autolysin complement of B. subtilis. We then review the known roles of autolysins at each stage in the life cycle, before considering how the activity of these potentially lethal enzymes is controlled in vivo. The lytic enzymes associated with prophages within the B. subtilis 168 chromosome are also briefly discussed. These are not autolysins sensu stricto because they are not host-encoded, but they are relevant because there appears to have been exchange of peptidoglycan hydrolase genes between $B$. subtilis and its phages. Lastly, we consider what opportunities arise from recent advances for a better understanding of the complex roles played by the autolysins of $B$. subtilis.

\section{B. subtilis autolysins and their substrate}

The vegetative cell is rod-shaped and surrounded by a wall $30-40 \mathrm{~nm}$ thick. The integrity of the wall depends almost exclusively on its peptidoglycan component, but the wall also contains anionic, covalently linked secondary polymers (teichoic acids or teichuronic acids). The structure of nascent $B$. subtilis peptidoglycan is an alternating copolymer of GlcNAc and MurNAc with pentapeptide side-chains branching from the MurNAc residues (Fig. 1). The glycan backbone is polymerized in situ by transglycosylation and cross-links are formed by transpeptidation between the penultimate $\mathrm{D}$-alanine of one peptide side-chain and the free amino group of the meso-diaminopimelate $\left(\mathrm{A}_{2} \mathrm{pm}\right)$ of another (Archibald et al., 1993). This structure affords four classes of bond that can be hydrolysed to result in bulk, potentially bacteriolytic, disruption of the cross-linked structure. 

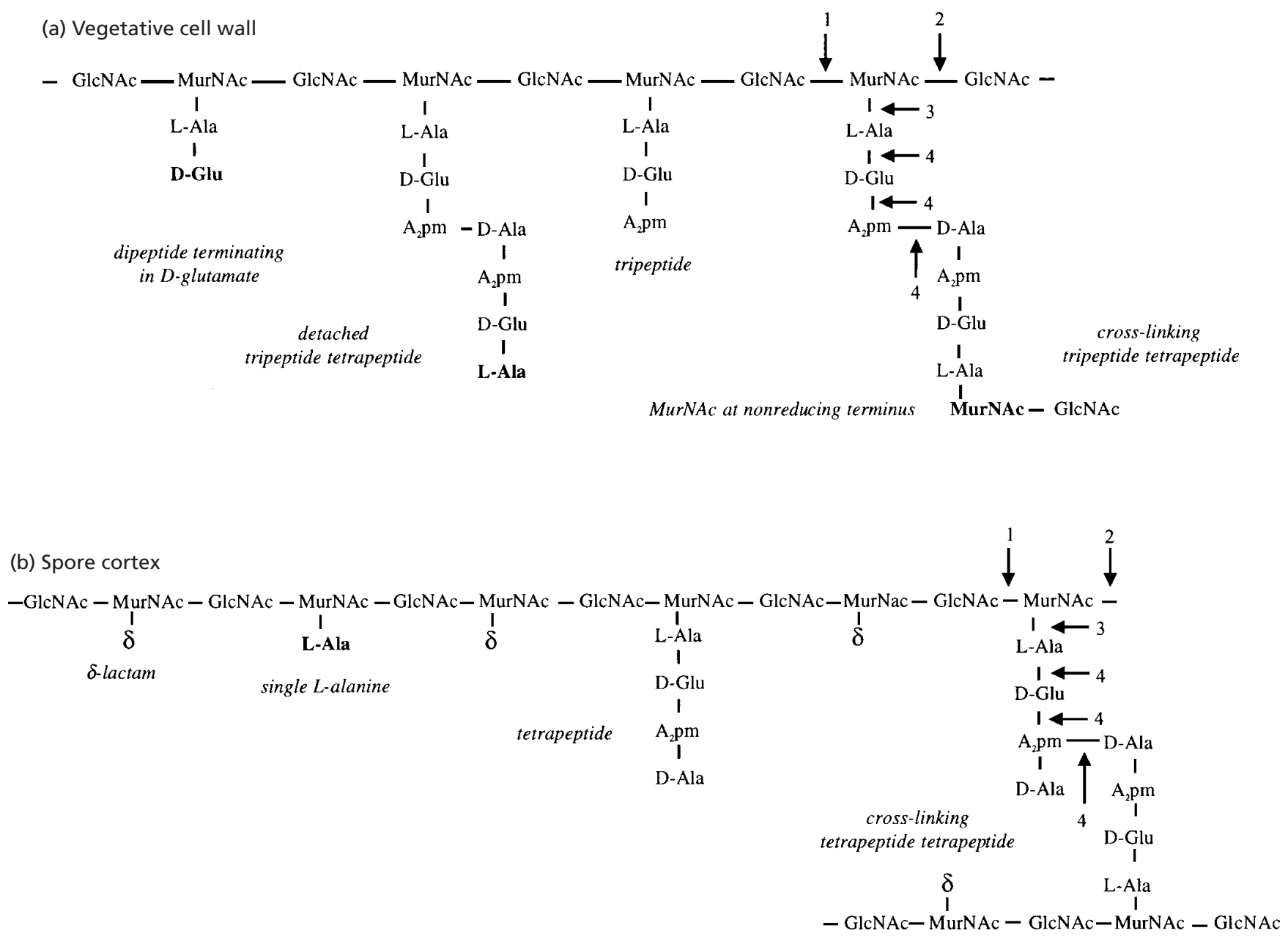

Fig. 1. Simplified schematic structure of mature $B$. subtilis peptidoglycan from vegetative cell walls (a) and spore cortex (b). An example of each type of bond attacked by glucosaminidase (1), muramidase/lytic transglycosylase (2), amidase (3) and endopeptidase (4) is indicated by arrows on each structure. Terminal groups and other features of the mature structure that are, or appear to be, due to autolysin action are shown in bold.

Hence, autolysins can be classified as muramidases, glucosaminindases, $\mathrm{N}$-acetylmuramoyl-L-alanine amidases (amidases) and endopeptidases, according to their hydrolytic bond specificity (Ghuysen et al., 1966; Fig. 1a). In addition, lytic transglycosylases break the same bond as muramidases, but yield anhydromuropeptides as products (Höltje et al., 1975). Other peptidoglycan hydrolases are not autolysins, since they cannot, on their own, cause cell lysis (Foster, 1994).

\section{The autolysin complement of $B$. subtilis}

The proposed peptidoglycan hydrolase complement of B. subtilis (Table 1) was compiled by performing aminoacid sequence similarity searches of the SubtiList genome sequence database (Kunst et al., 1997). Representatives of all known classes of autolysins and phage lytic enzymes were used as query sequences. In total, 35 definite or probable peptidoglycan hydrolase genes were identified in the B. subtilis genome, which clustered into 11 families on the basis of amino acid sequence similarities. This multiplicity of autolysin genes in the $B$. subtilis genome is consistent with the previous zymographic detection of at least 15 autolytic polypeptides in cells during various stages of the life cycle (Foster, 1992; Rashid et al., 1995a; Smith \& Foster, 1997; Blackman et al., 1998). The major characteristics of each of the families and their members are described below.

\section{LytC amidase family}

Members of the LytC amidase family are homologous to the C-terminal 175 aa of the B. subtilis amidase LytC, which appears to contain the murolytic domain (Kuroda \& Sekiguchi, 1991; Lazarevic et al., 1992).

\section{LytD glucosaminidase family}

This contains only LytD itself, which is one of the major autolysins of vegetative growth. Autolytic activity resides within the C-terminal region (aa 569-880; Margot et al., 1994; Rashid et al., 1995b). The catalytic 
domain of LytD is also homologous to the glucosaminidase domain (aa 776-1256) of the bifunctional autolysin, Atl, of Staphylococcus aureus (Foster, 1995; Oshida et al., 1995).

\section{DL-Endopeptidase I family}

Bacillus sphaericus produces two endopeptidases of diverse primary structure that cleave the peptide bond between D-Glu and $\mathrm{A}_{2} \mathrm{pm}$ (Hourdou et al., 1992, 1993). The $45 \mathrm{kDa}$ zinc-requiring, sporulation-related endopeptidase I of B. sphaericus belongs to a large family of zinc-active-site peptidases with a variety of functions (Hourdou et al., 1993). Its catalytic domain (aa 101-396) has one significant homologue in B. subtilis, YqgT, which constitutes the DL-endopeptidase I family (Table 1) and may also be sporulation specific.

\section{DL-Endopeptidase II family}

This family comprises homologues of endopeptidase II of B. sphaericus (Hourdou et al., 1992), which are also related to the C-terminal 120 aa (the presumed autolytic domain) of the p60 autolysin of Listeria monocytogenes (Wuenscher et al., 1993). The experimentally determined bond specificity of B. sphaericus endopeptidase II (Hourdou et al., 1992) and LytF (Margot et al., 1999; Ohnishi et al., 1999) of B. subtilis suggests that all these enzymes are $\gamma$-D-glutamyl-L-diamino acid endopeptidases that hydrolyse the peptide bond between $\mathrm{D}-$ glutamate and $\mathrm{A}_{2} \mathrm{pm}$. All the members of this family from B. subtilis, as well as endopeptidase II and p60, have an apparently catalytically essential cysteine residue within a conserved DCS $(\mathrm{G} / \mathrm{S}$ ) motif (Hourdou et al., 1992).

\section{Lysostaphin family}

Searching the B. subtilis genome with the central catalytic portion (aa 236-383; Baba \& Schneewind, 1996) of lysostaphin from Staphylococcus simulans (Recsei et al., 1987) revealed the lysostaphin family of possible peptidoglycan hydrolases, which has three members, YomI, YunA and SpoIIQ. Lysostaphin is an endopeptidase that hydrolyses the pentaglycine moieties that cross-link the branch peptides of $S$. aureus peptidoglycan (Schindler \& Schuhardt, 1964). The pentaglycine moiety has not been detected in B. subtilis peptidoglycan and so some of the lysostaphin homologues in Table 1 may act as antibiotics to kill staphylococci. Others may have different substrate specificity from lysostaphin or act on very rare unusual cross-links that have not yet been detected. One member of this family, YomI, a large protein with two apparently unrelated potential autolytic domains, also belongs to the Slt70 family.

\section{Germination-specific lytic enzyme (GSLE) family}

The GSLE family was uncovered by searching with the GSLE, SleB, of Bacillus cereus. SleB of B. cereus is a probable amidase that is released by germinating spores and has a role in germination (Makino et al., 1994). However, SleB of B. subtilis is likely to be a lytic transglycosylase (Boland et al., 2000).

\section{LD-Endopeptidase family}

Searching with the L-alanoyl-D-glutamate endopeptidase AepA of the L. monocytogenes phage A500 (Loessner et al., 1995) revealed a single significant homologue (YcdD) in B. subtilis, which constitutes the LD-endopeptidase family.

\section{Slt70 family}

Two homologues of the lytic transglycosylase Slt70 of $E$. coli constitute the Slt70 family. Slt70 is unique among autolysins in that its X-ray crystal structure has been determined (Thunnissen et al., 1994). YomI and YjbJ, the Slt70 homologues in B. subtilis, are similar to Slt70 within its C-terminal domain (aa 451-618), which has a similar structure to lysozyme (a muramidase) and is believed to be the catalytic part of the molecule. The Nterminal 450 aa of Slt70, which may function in substrate binding (Thunnissen et al., 1994), is not significantly homologous to YomI or YjbJ, which may therefore recognize their substrates in quite different manners.

\section{Enterococcal muramidase family}

This contains YubE, which is homologous to the presumed catalytic N-terminal 200 aa of muramidase-2 from Enterococcus hirae (Joris et al., 1992). Searching with the homologous sequence of AlyS, a putative muramidase from Enterococcus faecalis (Joris et al., 1992), also revealed YpbE. YpbE is weakly homologous to both the N-terminal (presumed catalytic) and Cterminal (proposed cell-wall-binding) domains of AlyS, and so was tentatively assigned to the enterococcal muramidase family as well. There is a weak similarity between the muramidase- 2 and AlyS and some 100 aa within the catalytic domain of the major vegetative glucosaminidase LytD (Rashid et al., 1995b), suggesting some similarity between these two groups of hexosaminidases.

\section{LrgB family}

LrgB, a 233 aa putative autolysin from S. aureus (Brunskill \& Bayles, 1996), which shows no detectable sequence similarity to other identified families of enzymes, has three homologues in B. subtilis, which form the $\operatorname{LrgB}$ family.

\section{XlyA amidase family}

A family of seven potential peptidoglycan hydrolases was revealed by searching with the amidase XlyA of the B. subtilis prophage PBSX (Longchamp et al., 1994). This class of probable amidases is related to the amidase domain (aa 199-775) of the bifunctional S. aureus autolysin Atl (Foster, 1995; Oshida et al., 1995) and the 


\section{Table 1. Proposed peptidoglycan hydrolase complement of $B$. subtilis}

Candidate peptidoglycan hydrolases in the B. subtilis genome were identified by performing BLAsT-2 (Altschul et al., 1997) searches via the SubtiList web server (http://bioweb.pasteur.fr/GenoList/SubtiList/), using representatives of all known classes of peptidoglycan hydrolases from B. subtilis and other bacteria (both Gram-positive and Gram-negative). As described in the text, where query sequences were known to have several functional domains, only the sequence known to encode the autolytically active domain was used in the search. All hits with smallest sum probabilities $[P(\mathrm{n})]$ of $0 \cdot 01$ or less were considered potentially significant. These were then further tested by using them as query sequences in BLAST-2 searches of the whole nonredundant protein sequence database of the National Center for Biotechnology Information (http://www.ncbi.nlm.nih.gov/BLAST). If the highest scoring significant hits to proteins of known function at this stage were known peptidoglycan hydrolases, the $B$. subtilis sequence in question was considered likely to be an enzyme with similar activity and was included in the table. The reference sequence used for calculation of percentage identities for each family is shown in parenthesis after the name of the family.

\begin{tabular}{|c|c|c|c|c|c|c|c|c|}
\hline Protein & $\begin{array}{c}\text { Identity } \\
(\%) / \text { similarity } \\
(\%) / \text { aa overlap }\end{array}$ & $\begin{array}{c}\text { Molecular } \\
\text { mass } \\
(\mathrm{kDa})\end{array}$ & Location & $\begin{array}{c}\text { Estimated } \\
\text { pI }\end{array}$ & Expression & Activity* & Reference & Function \\
\hline \multicolumn{9}{|c|}{ LytC amidase family (LytC of $B$. subtilis, aa 322-496) } \\
\hline LytC (CwlB) & $100 / 100 / 175$ & $52 \cdot 4$ & Cell wall & $10 \cdot 11$ & $\begin{array}{l}\text { Vegetative }\left(\sigma^{\mathrm{A}} \text { and }\right. \\
\left.\sigma^{\mathrm{D}}\right) \text {, remains } \\
\text { active during } \\
\text { sporulation }\end{array}$ & Amidase & $\begin{array}{l}\text { Margot \& Karamata } \\
\text { (1992), Lazarevic et al. } \\
\text { (1992), Kuroda \& } \\
\text { Sekiguchi (1991), } \\
\text { Blackman et al. (1998), } \\
\text { Smith \& Foster (1995) }\end{array}$ & $\begin{array}{l}\text { Cell separation, wall } \\
\text { turnover; protein secretion } \\
\text { (?), cell lysis, mother-cell } \\
\text { lysis }\end{array}$ \\
\hline YqiI & $55 / 74 / 174$ & $22 \cdot 1$ & & $4 \cdot 29$ & & & & \\
\hline CwlC & $41 / 55 / 169$ & $27 \cdot 0$ & $\begin{array}{l}\text { Mother-cell } \\
\text { wall }\end{array}$ & $5 \cdot 94$ & & Amidase & $\begin{array}{l}\text { Kuroda et al. (1993), Smith } \\
\text { \& Foster (1995) }\end{array}$ & Mother-cell lysis \\
\hline CwlD & $35 / 58 / 187$ & $26 \cdot 9$ & & $9 \cdot 79$ & $\begin{array}{l}\text { Sporulation }\left(\sigma^{\mathrm{E}},\right. \\
\left.\sigma^{\mathrm{G}}\right)\end{array}$ & Amidase? & $\begin{array}{l}\text { Sekiguchi et al. (1995), } \\
\text { Atrih et al. (1996), } \\
\text { Popham et al. (1996a) }\end{array}$ & $\begin{array}{l}\text { Formation of muramic } \delta \text { - } \\
\text { lactam structure in spore } \\
\text { cortex, spore germination }\end{array}$ \\
\hline YrvJ & $33 / 56 / 175$ & $55 \cdot 3$ & & $5 \cdot 19$ & & & & \\
\hline \multicolumn{9}{|c|}{ LytD glucosaminidase family (LytD of B. subtilis, aa 569-880) } \\
\hline LytD (CwlG) & $100 / 100 / 312$ & $95 \cdot 4$ & Cell wall & $9 \cdot 94$ & $\begin{array}{l}\text { Vegetative, } \\
\text { primarily } \sigma^{\mathrm{D}}\end{array}$ & Glucosaminidase & $\begin{array}{l}\text { Margot et al. (1994), Rashid } \\
\text { et al. (1995b), Blackman } \\
\text { et al. (1998) }\end{array}$ & $\begin{array}{l}\text { Cell separation, cloxacillin- } \\
\text { induced cell lysis }\end{array}$ \\
\hline \multicolumn{9}{|c|}{ DL-Endopeptidase I family (endopeptidase I of B. sphaericus, aa 101-396) } \\
\hline YqgT & $45 / 63 / 296$ & $43 \cdot 2$ & & $5 \cdot 91$ & & & & \\
\hline \multicolumn{9}{|c|}{ DL-Endopeptidase II family (endopeptidase II of $\boldsymbol{B}$. sphaericus) } \\
\hline YddH & $34 / 47 / 89$ & $36 \cdot 4$ & & 8.63 & & & & Prophage 2 lysis? \\
\hline $\begin{array}{l}\text { LytF (CwlE, } \\
\text { YhdD) }\end{array}$ & $33 / 55 / 99$ & $51 \cdot 2$ & Cell wall & $10 \cdot 41$ & Vegetative $\left(\sigma^{\mathrm{D}}\right)$ & $\begin{array}{l}\gamma \text {-D-glutamyl- } \mathrm{A}_{2} \mathrm{pm} \\
\text { endopeptidase }\end{array}$ & $\begin{array}{l}\text { Margot et al. (1999), } \\
\text { Ohnishi et al. (1999) }\end{array}$ & Cell separation \\
\hline YojL & $33 / 55 / 103$ & $44 \cdot 1$ & Cell wall & $10 \cdot 44$ & & & $\begin{array}{l}\text { T. J. Smith and others, } \\
\text { unpublished }\end{array}$ & \\
\hline YwtD & $32 / 53 / 107$ & $45 \cdot 1$ & & $8 \cdot 52$ & & & & \\
\hline LytE (CwlF) & $35 / 57 / 106$ & $37 \cdot 2$ & & $10 \cdot 71$ & $\begin{array}{l}\text { Vegetative }\left(\sigma^{\mathrm{A}}\right) \text { and } \\
\text { late stationary } \\
\text { phase }\left(\sigma^{\mathrm{H}}\right)\end{array}$ & & $\begin{array}{l}\text { Margot et al. (1998), } \\
\text { Ishikawa et al. (1998a) }\end{array}$ & Cell separation, cell lysis \\
\hline YkfC & $47 / 73 / 115$ & $32 \cdot 9$ & & $6 \cdot 35$ & Late vegetative & & $\begin{array}{l}\text { T. J. Smith \& S. J. Foster, } \\
\text { unpublished }\end{array}$ & \\
\hline YvcE $\quad$ & $31 / 56 / 116$ & $50 \cdot 8$ & & $5 \cdot 33$ & & & & \\
\hline \multicolumn{9}{|c|}{ Lysostaphin family (lysostaphin of $S$. simulans, aa 236-383) } \\
\hline YomI $\dagger$ & $50 / 71 / 129$ & 252 & & $8 \cdot 27$ & & & & $\mathrm{SP} \beta$-mediated lysis? \\
\hline YunA & $42 / 65 / 117$ & $39 \cdot 5$ & & 6.89 & & & & \\
\hline SpolIQ & $34 / 52 / 102$ & $31 \cdot 0$ & & $4 \cdot 47$ & Sporulation $\left(\sigma^{\mathrm{F}}\right)$ & & $\begin{array}{l}\text { Londoño-Vallejo et al. } \\
\text { (1997) }\end{array}$ & Prespore engulfment \\
\hline \multicolumn{9}{|c|}{ GSLE family (SleB of B. cereus) } \\
\hline SleB & $63 / 76 / 169$ & $33 \cdot 8$ & & $9 \cdot 51$ & Sporulation $\left(\sigma^{G}\right)$ & $\begin{array}{l}\text { Lytic } \\
\text { transglycosylase? }\end{array}$ & $\begin{array}{l}\text { Moriyama et al. (1996), } \\
\text { Boland et al. (2000) }\end{array}$ & Germination \\
\hline YkvT & $35 / 64 / 137$ & $23 \cdot 2$ & & 9.79 & & & & \\
\hline CwlJ & $35 / 59 / 118$ & $16 \cdot 2$ & & $9 \cdot 35$ & Sporulation $\left(\sigma^{\mathrm{E}}\right)$ & & Ishikawa et al. (1998b) & Germination \\
\hline \multicolumn{9}{|c|}{ LD-Endopeptidase family (endopeptidase AepA of L. monocytogenes phage A500) } \\
\hline YcdD & $54 / 70 / 106$ & $19 \cdot 0$ & & 5.66 & & & & \\
\hline \multicolumn{9}{|c|}{ Slt 70 family (Slt70 of E. coli) } \\
\hline YjbJ & $39 / 56 / 99$ & $18 \cdot 8$ & & $7 \cdot 02$ & Vegetative & & Blackman (1998) & None during germination \\
\hline YomI $†$ & $48 / 67 / 151$ & 252 & & $8 \cdot 27$ & & & & $\mathrm{SP} \beta$-mediated lysis? \\
\hline \multicolumn{9}{|c|}{ Enterococcal muramidase family (AlyS of E. faecalis) } \\
\hline YubE & $38 / 86 / 151$ & $31 \cdot 7$ & & $8 \cdot 28$ & & & & \\
\hline YpbE & $32 / 31 / 131$ & $27 \cdot 1$ & & $5 \cdot 43$ & & & & \\
\hline \multicolumn{9}{|c|}{ LrgB family (LrgB of $S$. aureus) } \\
\hline YsbB & $58 / 75 / 223$ & $24 \cdot 3$ & & $9 \cdot 81$ & & & & \\
\hline YwbG & $34 / 59 / 213$ & $25 \cdot 7$ & & $9 \cdot 56$ & & & & Cell separation \\
\hline $\mathrm{YxaC}$ & $33 / 56 / 167$ & $32 \cdot 7$ & & $9 \cdot 02$ & & & & \\
\hline \multicolumn{9}{|c|}{ XlyA amidase family (XlyA of B. subtilis prophage PBSX) } \\
\hline XlyA & $100 / 100 / 297$ & $31 \cdot 8$ & & $5 \cdot 34$ & PBSX induction & Amidase & Longchamp et al. (1994) & PBSX-mediated lysis \\
\hline XlyB & $57 / 73 / 149$ & $33 \cdot 7$ & & $9 \cdot 80$ & & & & PBSX-mediated lysis? \\
\hline YqeE (CwlH) & $66 / 76 / 192$ & $27 \cdot 4$ & & $10 \cdot 0$ & & & Nugroho et al. (1999) & Mother-cell lysis \\
\hline CwlA & $64 / 75 / 90$ & $29 \cdot 8$ & & $10 \cdot 4$ & Apparently silent & Amidase & $\begin{array}{l}\text { Foster (1991, 1993), Kuroda } \\
\text { \& Sekiguchi (1990) }\end{array}$ & skin-mediated lysis? \\
\hline BlyA (YomC) & $37 / 44 / 114$ & $39 \cdot 5$ & & $9 \cdot 94$ & $\mathrm{SP} \beta$ induction & Amidase & $\begin{array}{l}\text { Regamey \& Karamata } \\
\text { (1998) }\end{array}$ & $\mathrm{SP} \beta$-mediated lysis \\
\hline YdhD & $37 / 64 / 62$ & $48 \cdot 8$ & & $9 \cdot 07$ & & & & \\
\hline YocH & $42 / 59 / 49$ & $30 \cdot 0$ & & $8 \cdot 37$ & & & & \\
\hline
\end{tabular}

*Enzymic activity is stated only where experimental evidence is available.

†YomI is homologous to both lysostaphin and Slt70, which show no significant sequence similarity to one another. Similarity to lysostaphin is strongest between aa 1508 and 1682 of YomI, and the similarity to Slt70 is strongest between aa 1375 and 1539 , suggesting that YomI may have two peptidoglycan hydrolase domains. 
amidase domain (aa 31-261) of the Ami amidase of $L$. monocytogenes (McLaughlan \& Foster, 1998; Braun et al., 1997), but they show no detectable primary structure relationship to the amidases of the LytC class. As detailed below, several of these may be involved in cell lysis following prophage induction.

\section{Accuracy of assignment and general features of the autolysin complement}

Although it is expected that the assignment of autolysins presented here is quite robust, it is anticipated that the working inventory of $B$. subtilis autolysins presented in Table 1 will evolve as more information becomes available. It is likely that at least a few gene products in Table 1 do not function as autolysins because they are high-scoring false positives from the BLAST-2 searches, or because they are genuine autolysin homologues that do not function as autolysins. Such enzymes may have evolved other functions, perhaps in the hydrolysis of polysugar-containing molecules other than peptidoglycan. Conversely, some autolysins may have escaped detection during the current study because of low sequence similarity to known autolysins, or because the ORFs encoding them have not yet been detected owing to sequencing errors or overlaps between genes (Kunst et al., 1997).

Many peptidoglycan hydrolases, from B. subtilis and other organisms, have noncatalytic domains, often containing tandem repeats, that are involved in binding to the cell wall (Joris et al., 1992; Wuenscher et al., 1993; Lazarevic et al., 1992; Ghuysen et al., 1994; Baba \& Schneewind, 1998). The precise molecular nature of this recognition has yet to be elucidated, but it appears that anionic secondary polymers may be important (Lazarevic et al., 1992). This modular design may have allowed interchange of catalytic and binding domains among autolysins and other wall-associated proteins during evolution. For instance, three members of the DLendopeptidase II family (LytE, LytF and YojL) from $B$. subtilis are homologous within their N-terminal, probable wall-binding regions, to the putative wall-binding domain (aa 201-666) of muramidase-2 from E. hirae (Joris et al., 1992), although they have no detectable sequence similarity to the proposed catalytic domain of muramidase-2. YwtD, another member of the endopeptidase II family, strangely appears to have the endopeptidase II catalytic motif repeated three times, but only the central one has the catalytically important Cys. Maybe this domain is catalytic and the rest are involved only in substrate recognition. YocH, which is homologous to the amidase XlyA, also has repeats homologous to those of the endopeptidase II family but lacks the Cys at the proposed active centre of those enzymes.

A few B. subtilis gene products show significant similarity only to apparently non-catalytic, probable wallbinding parts of known autolysins. Some or all of these proteins may be wall-associated but not autolysins. Several wall-associated non-autolysins appear to modu- late autolysin activity, such as $\mathrm{LytB}$, which enhances LytC activity (Lazarevic et al., 1992), and WapA, which modulates the effect of autolysin mutations on motility (Blackman et al., 1998). Also, SpoIID, which is homologous to LytB and the wall-binding domain of LytC, may also have a role in autolysin activation (Kuroda et al., 1992; Lazarevic et al., 1992; Illing \& Errington, 1991).

Most wall-associated proteins, including autolysins, are expected to have high $\mathrm{pI}$, since they are associated with the negatively charged cell wall. As can be seen in Table 1 , most known autolysins are basic proteins, but we do not consider high estimated $\mathrm{pI}$ as a criterion for discounting a potential autolysin without further experimental evidence. Such a protein may still have access to the cell wall by being either membrane-associated or one of the so-called 'periplasmic' proteins that are extracytoplasmic cell-associated proteins that remain bound to the cell wall when the cells are broken (Merchante et al., 1995). Likewise, absence of a detectable signal sequence does not necessarily suggest that a particular enzyme is not secreted and so does not have access to the cell wall, as other mechanisms of secretion exist (Kuchler, 1993). For instance, CwlC, the major amidase during late sporulation, has no signal sequence but has been shown to be present in the cell wall (Kuroda et al., 1993; Smith \& Foster, 1995).

\section{Roles of autolysins}

\section{Involvement of autolysins during vegetative growth}

The life cycle of B. subtilis shown in Fig. 2a highlights the processes during vegetative growth in which autolysins have been proposed to be involved. The roles played by individual enzymes in each process have been studied by constructing specifically inactivated mutants. The effects of inactivating the two major autolysins of vegetative growth (the amidase $\mathrm{LytC}$ and the glucosaminidase LytD), which together account for about $95 \%$ of the autolytic activity of the cell, have been investigated in detail by several groups (Lazarevic et al., 1992; Kuroda \& Sekiguchi, 1991; Margot et al., 1994; Margot \& Karamata, 1992; Rashid et al., 1995b; Blackman et al., 1998). The effects of other, minor, although apparently important, autolysins are only just beginning to be uncovered. The various studies have produced somewhat different results, probably because of slight differences in genetic background and experimental conditions. Nonetheless, a general picture has emerged in which there is a high degree of functional redundancy among a number of multifunctional enzymes.

Peptidoglycan maturation. Nascent peptidoglycan is synthesized on the outer surface of the cytoplasmic membrane from disaccharide pentapeptide building blocks which are polymerized by transglycosylation to give the glycan strands and cross-linked by transpeptidation. Both these reactions are performed by highmolecular-weight penicillin-binding proteins (Ghuysen, 1991). Determination of peptidoglycan fine structure has 
(a) Vegetative growth
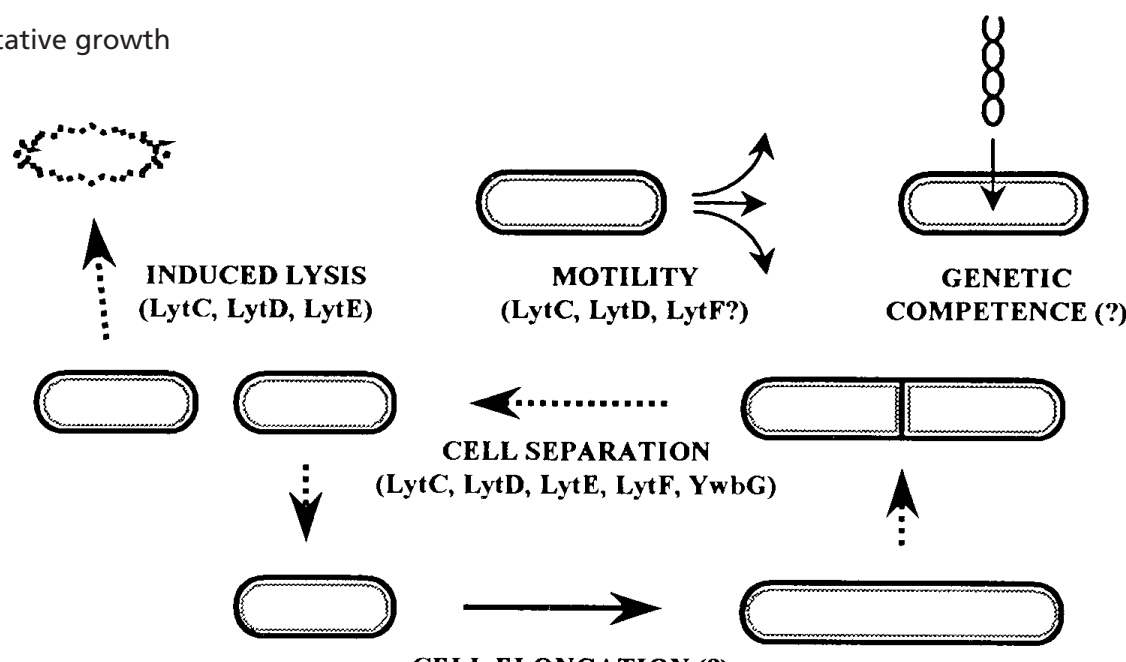

CELL ELONGATION (?), PEPTIDOGLYCAN MATURATION (?) and CELL WALL TURNOVER (LytC, LytD)

(b) Sporulation
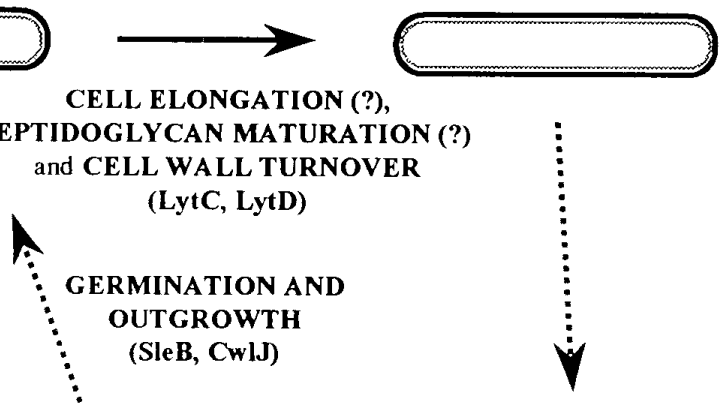

\section{(?)}
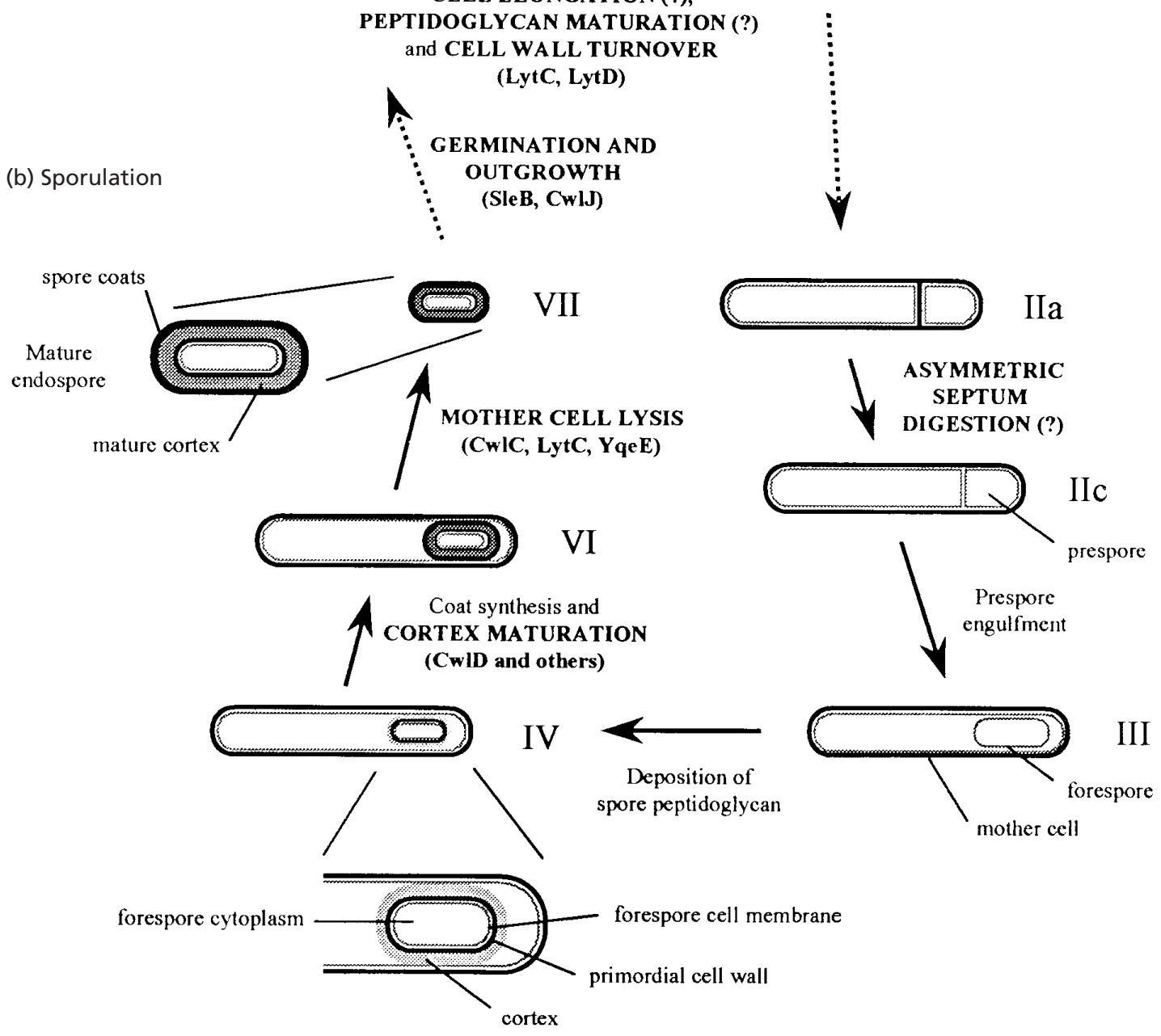

Fig. 2. Life cycle of $B$. subtilis. Processes that require or appear to require autolysin activity are labelled in bold capitals, and autolysins involved, where known, are indicated in parenthesis after each. (a) Vegetative growth. The steps of the vegetative growth cycle apart from cell elongation are linked by broken arrows, as each step is not absolutely dependent on previous steps. Cell separation, motility and genetic competence occur primarily in stationary phase. (b) Sporulation. Events during sporulation are linked by solid arrows because they occur in a precise, genetically controlled order. Roman numerals refer to the stages of sporulation (Doi, 1989). 
revealed subsequent modifications of peptidoglycan structure (maturation), some of which appear to require autolysins (Atrih et al., 1999; Fig. 1a).

The mature glycan strands can have MurNAc at the nonreducing terminus, suggesting that glucosaminidase activity has taken place (Atrih et al., 1999). This activity can be provided by LytD (Margot et al., 1994; Rashid et al., 1995b), which is the only glucosaminidase in the $B$. subtilis genome that is currently identifiable by sequence similarity. However, a lytD mutant still exhibits the glucosaminidase product in its peptidoglycan and so at least one other enzyme is responsible (A. Atrih \& S. J. Foster, unpublished). Peptide side-chains terminating in D-glutamate suggest the action of a D-glutamate-mesodiaminopimelate endopeptidase, which may be among the two identified DL-endopeptidase families (Table 1). The existence in vegetative cell walls of MurNAc residues with complete cross-link peptides severed from the other glycan strand beyond the distal L-alanine indicates amidase activity. The presence of anhydromuropeptides strongly suggests the action of one or more lytic transglycosylase (Atrih et al., 1999).

Cell separation, motility and competence. Wild-type $B$. subtilis cells exist as short chains or, in stationary phase, primarily as single cells. Cell separation is probably important in facilitating dispersion of cells and allowing them to chemotact towards nutritionally favourable environments. Many autolysin-deficient mutants show abnormally long chains without changes in the dimensions of individual cells. This suggests involvement of autolysins in digesting peptidoglycan from the middle of the division septum to allow daughter cells to separate. Five gene products are known to have roles in cell separation. These are the amidase $\mathrm{LytC}$, the glucosaminidase LytD, two members of the DL-endopeptidase II family (LytE and $\mathrm{LytF}$ ) and the putative autolysin YwbG. There is considerable functional redundancy among these proteins: where multiple mutants have been constructed, inactivation of more autolysins generally causes the bacteria to form longer chains of cells (Blackman et al., 1998; Ishikawa et al., 1998a; Margot et al., 1998, 1999; Ohnishi et al., 1999; G. Horsburgh \& S. J. Foster, unpublished). It is still unclear whether the functional redundancy of the autolysins involved in cell separation is complete, or whether certain steps in the process can be performed by some proteins but not others.

Early discovered regulatory mutants deficient in autolysins were immotile and so it was suggested that these enzymes were required for motility (Pooley \& Karamata, 1984a, b). It is now clear that expression of the two major vegetative autolysins $\mathrm{LytC}$ and $\mathrm{LytD}$, as well as the endopeptidase LytF, are largely coregulated with the genes required for flagellar motility and chemotaxis via the regulatory genes $\operatorname{sig} D$ and $\sin R$ (Lazarevic et al., 1992; Rashid \& Sekiguchi, 1996; Margot et al., 1999), strongly suggesting that these autolysins are involved in motility. Inactivation of the amidase LytC causes diminished swarming motility (Blackman et al., 1998; Margot et al., 1994; Rashid et al., 1995b) and, under some conditions, the glucosaminidase LytD also has a role in this process (Blackman et al., 1998; Rashid et al., 1995b). The effect of these autolysin mutations on motility may be due at least partly to their effect on cell separation, which predominates in stationary phase, probably to facilitate motility. Uncoordinated chemotaxis of cells linked together in chains may produce less overall movement than when the cells can move separately, the pushmi-pullyu effect (Blackman et al., 1998). The roles of other autolysins in motility, and the possibility that autolytic activity may be needed for extrusion of flagella through the cell wall (Dijkstra \& Keck, 1996) remain to be investigated. Likewise, the suggested involvement of autolysins in genetic competence, which was also inferred from pleiotropic mutants (Pooley \& Karamata, 1984a), has not yet been fully tested.

Cell expansion, cell-wall turnover and protein secretion. Electron microscopy shows the wall as comprising three distinct layers (Graham \& Beveridge, 1994). Pulse-labelling studies suggest an inside-to-outside flux of wall material, new wall being laid down along the cytoplasmic membrane and removed from the exterior by autolysins (Merad et al., 1989; Pooley, 1976). The inner zone of the wall may contain newly synthesized, unstressed peptidoglycan. As the cell elongates, this material passes outward and stretches, becoming the middle, stress-bearing zone. The outer zone may thus consist of old, partially hydrolysed peptidoglycan awaiting solubilization (Graham \& Beveridge, 1994). This inside-to-outside model of wall structural dynamics suggests that autolysins are necessary for hydrolysis of older peptidoglycan to allow newer peptidoglycan to expand and become stress bearing as the cell elongates, and to remove the oldest wall material from the outer surface (i.e. cell-wall turnover).

The inside-to-outside model for cell-wall growth suggests that breakage of covalent bonds within the peptidoglycan is essential for cell growth. Consistent with this, an early study found that exogenous addition of an autolysin-containing preparation could accelerate the growth rate (Fan \& Beckman, 1971). However, since individual autolysin genes have been identified and inactivated, no single or multiple autolysin mutant has shown a serious defect in growth rate. In view of the functional redundancy observed with other autolysin functions, it may be that enzyme(s) capable of performing the essential hydrolytic events have already been inactivated, but suitable multiple mutants for detection of their roles in cell expansion have not yet been constructed. Alternatively, expansion of the cell may cause such great stress forces in the outer layers of the cell wall that critical covalent bonds are fractured without the need for enzyme-catalysed hydrolysis (Archibald et al., 1993).

Although no link between autolytic activity and cell growth has been clearly established, the role of autolysins in cell-wall turnover has been convincingly proven. The major vegetative amidase $\mathrm{LytC}$ is important in this process. One study reported that its inactivation 
delayed the release of radiolabelled wall material in pulse-chase experiments without affecting the subsequent rate of turnover (Margot \& Karamata, 1992), whilst another found that LytC inactivation caused cellwall and septal thickening and a large decrease in the rate of turnover (Blackman et al., 1998). Inactivation of lytD alone has no effect on turnover (Margot et al., 1994), but absence of the glucosaminidase LytD further retards turnover in a lytC background. A minor autolysin controlled by $\sigma^{\mathrm{D}}$, possibly the endopeptidase LytF, also functions in peptidoglycan turnover (Blackman et al., 1998).

The cross-linked covalent network of peptidoglycan in bacterial cell walls can present a physical barrier to secretion of proteins, which may be lessened by the action of autolysins (Dijkstra \& Keck, 1996). Preliminary results in our laboratory suggest that inactivation of $l y t C$ and/or $l y t D$ impedes secretion of proteins by $B$. subtilis (Blackman, 1998). This effect may be at least partly due to the proposed requirement of cell-wall turnover for secretion of large proteins (Koch, 1995).

\section{Involvement of autolysins during differentiation}

The differentiation processes of sporulation and subsequent germination require a number of rearrangements and modifications of cell-wall peptidoglycan that include at least four events in which autolysins are likely to be involved (Fig. 2b; Smith et al., 1996). The first morphological change during sporulation is an asymmetric cell division (sporulation stage II) that produces daughter cells of unequal sizes. The smaller cell is the prespore, which develops into the endospore, and the larger compartment is the mother cell. The mother cell engulfs the prespore (sporulation stage III), which is thereafter known as the forespore. Two layers of peptidoglycan are laid down around the forespore (stage IV; Doi, 1989). The forespore lays down the inner layer, which is the primordial cell wall; the outer layer, the cortex, is derived from the mother cell (Tipper \& Linnett, 1976). Proteinaceous coat layers develop around the forespore, which matures into a phase-bright, resistant endospore (stages V and VI). Finally, the mother cell lyses and releases the mature endospore (stage VII; Doi, 1989). Despite its high level of resistance and quiescent state, the spore retains an alert sensory mechanism that can respond to specific germinants within minutes.

Asymmetric septum digestion. The first stage at which autolysin activity appears necessary for sporulation is hydrolysis of the asymmetric septum to permit prespore engulfment. The autolysins involved have not been identified, but mutation of spoIID halts sporulation at stage IIb, when the septum is partially removed and remains as an annulus around the edge of the division plane (Illing \& Errington, 1991). SpoIID is homologous to $\mathrm{LytB}$, the modifier protein that enhances the activity of the major vegetative amidase LytC (Herbold \& Glaser, 1975; Lazarevic et al., 1992; Kuroda et al., 1992). Completion of asymmetric septum digestion may require activation of one or more autolysins by SpoIID.
The lysostaphin homologue SpoIIQ also has a role in prespore engulfment, although apparently not in septum hydrolysis, because a spoIIQ-inactivated mutant is blocked after the septum has disappeared (LondoñoVallejo et al., 1997).

Cortex maturation. The unique structure of cortical peptidoglycan, which is essential for maintaining the heat resistance and dormancy of the spore, indicates the action of autolysins in its maturation (Fig. 1b). About $50 \%$ of the disaccharide subunits in the cortex have the muramic acid $\delta$-lactam structure (Fig. 1b), which is found only in bacterial endospores. The $\delta$-lactams are not randomly distributed, but occur predominantly at every alternate disaccharide. Two mechanisms have been proposed for $\delta$-lactam formation: amidase action followed by transacylation, or de- $\mathrm{N}$-acetylation followed by transpeptidation (Tipper \& Gauthier, 1972). Inactivation of $c w l D$, which encodes a sporulationspecific putative amidase belonging to the LytC family (Table 1), results in complete loss of the $\delta$-lactam structure (Atrih et al., 1996; Popham et al., 1996a). Thus amidase activity appears to be essential for producing this characteristic structure of cortical peptidoglycan.

Cortical peptidoglycan is very loosely cross-linked, at only $2.9 \%$ of muramic acid residues (Atrih et al., 1996), compared to $29-33 \%$ in vegetative cell walls (Atrih et al., 1999). The anisotropic swelling theory of cortex expansion during forespore maturation suggests that the cortex is first synthesized with a relatively large number of peptide cross-links; selective enzymic cleavage of these reduces the cross-linking index and leads to radial expansion of the cortex causing inward mechanical pressure on the spore core. This pressure prevents the core taking up water and swelling, and thus the action of autolysins during cortex maturation may be essential in maintaining the spore in its dehydrated, quiescent state (Warth, 1978). Alternatively, or in addition, DDcarboxypeptidase activity may prevent cross-link formation by removing C-terminal D-Ala residues from D-Ala-D-Ala-terminating peptide side-chains. This is supported by studies showing that mutations in the sporulation-specific penicillin-binding proteins $\mathrm{DacB}$ and DacF result in increased cross-linking (Atrih et al., 1996; Popham et al., 1996b, 1999), showing that the cross-linking index of cortical peptidoglycan is at least partly controlled at the level of cross-link formation. The possible role of specific autolysin-catalysed crosslink hydrolysis in determining the final cross-linking index of mature cortex has yet to be fully investigated.

About $25 \%$ of the muramic acid residues in the cortex have single L-alanine side-chains (Fig. 1b; Atrih et al., 1996; Popham et al., 1996b). These may be formed from longer side-chains by the action of an L-alanoyl-Dglutamate endopeptidase. This suggests a role for $Y \mathrm{cdD}$, the only putative autolysin of $B$. subtilis predicted to have such activity (Table 1 ). However, our recent data have shown that a $y c d D$ mutant is still able to produce single L-alanine side-chains. Alternatively, the single L-alanine side-chains may result from sequential carboxypeptidase-catalysed steps. 
Mother-cell lysis. Mother-cell lysis at the end of sporulation, which is required for release of the mature endospore, depends on two amidases of the LytC family, CwlC and LytC itself. CwlC and LytC have mutually compensatory roles in hydrolysis of mother-cell-wall peptidoglycan and so mother-cell lysis is blocked only when both are absent (Foster, 1992; Smith \& Foster, 1995). Recent results have shown that YqeE, which belongs to the XlyA amidase family, also has a role in mother-cell lysis (Nugroho et al., 1999).

Germination. The importance of the cortex in maintaining endospore dehydration, resistance and dormancy demands its selective hydrolysis as one of the necessary events of germination, to allow uptake of water, core expansion and outgrowth (Foster \& Johnstone, 1990). Analysis of spore peptidoglycan and material released during germination shows that a subtle change, probably stereochemical, occurs at or near to the muramic $\delta$-lactam (Atrih et al., 1998). Concomitantly, hydrolytic events, primarily lytic transglycosylase and, to a lesser extent, glucosaminidase, cause release of the cortical peptidoglycan as muropeptide fragments (Atrih et al., 1998). Detectable peptidoglycan modification and hydrolysis are relatively late events in germination, being undetectable until 3 min after addition of germinant, by which time heat resistance has already begun to be lost and dipicolinate from the spore is released (Atrih et al., 1998). It appears to be the muramic $\delta$-lactam that targets the cortex for digestion during germination, because the $c w l D$ mutant, which lacks the $\delta$-lactam, produces resistant endospores but does not undergo cortex hydrolysis during germination and cannot outgrow (Atrih et al., 1996, 1998; Popham et al., 1996b; Sekiguchi et al., 1995). This specificity ensures that the primordial cell wall, which appears not to have the $\delta$-lactam, is not hydrolysed and remains to develop into the cell wall of the outgrowing spore. Little or no muramidase activity was observed during germination (Atrih et al., 1998). Consistent with this, the germination-specific muramidase SleM found in Clostridium perfringens (Chen et al., 1997) has no detectable homologue in B. subtilis.

GSLEs, which catalyse germination-like changes in permeabilized spores, have been isolated from germinating endospores in other species (reviewed by Atrih \& Foster, 1999) and are weakly related to the XlyA amidase family. B. subtilis has three GSLE homologues, SleB, CwlJ and YkvT. The roles of SleB and CwlJ have been studied at the molecular level. Both have roles in the later stages of germination, and a sleB cwlJ double mutant is completely blocked in cortex hydrolysis and outgrowth (Ishikawa et al., 1998b). The sleB mutant, which showed retarded germination, demonstrated no evidence of lytic transglycosylase activity during germination (Boland et al., 2000). Thus, the GSLE SleB must be either a lytic transglycosylase or a protein with a different specificity whose action is necessary before the lytic transglycosylase can act. YjbJ, the only putative lytic transglycosylase that is not prophage-encoded, is not likely to be involved in germination because its inactivation caused no detectable germination deficiency (Blackman, 1998) or lack of anhydromuropeptides during germination (A. Atrih \& S. J. Foster, unpublished). Activity of sleB (but apparently not $c w l J)$ depends on $y p e B$, which encodes a protein of unknown function and is immediately downstream from sleB in the same apparent two-gene operon. $y p e B$ is conserved in other endospore-forming bacteria (Boland et al., 2000). The glucosaminidase activity observed during germination is due to an unidentified enzyme, as a lytD or cwlJ mutant still demonstrates generation of the products.

\section{Control of autolysins}

Where transcriptional control of autolysins has been investigated, it is generally consistent with the proposed roles of the proteins concerned (Table 1). Expression of the major vegetative autolysin genes $l y t C$ and $l y t D$, together with the minor vegetative endopeptidase gene $l y t F$, is dependent primarily on the flagellar motility and chemotaxis sigma factor, $\sigma^{\mathrm{D}}$, which peaks in activity at the start of stationary phase (Lazarevic et al., 1992; Kuroda \& Sekiguchi, 1993; Margot et al., 1994, 1999; Helmann et al., 1988). This concurs with their roles in cell separation and motility, which predominate around the same time. About $20 \%$ of $l y t C$ expression is directed by the major vegetative housekeeping sigma factor, $\sigma^{\mathrm{A}}$ (Kuroda \& Sekiguchi, 1991; Lazarevic et al., 1992; Margot et al., 1999), consistent with a requirement for the LytC amidase in cell-wall turnover and some cell separation throughout vegetative growth. The presumed vegetative endopeptidase gene $l y t E$, also involved in cell separation, is controlled by $\sigma^{\mathrm{A}}$ and the late stationary phase/early sporulation sigma factor $\sigma^{\mathrm{H}}$ (Margot et al., 1998; Ishikawa et al., 1998a), suggesting that it functions in late post-exponential processes. The expression of the autolysins and putative autolysins involved during sporulation is again consistent with their known functions. All are controlled temporally and in a compartment-specific manner by the complex interdependent sporulation control machinery, via one or more of the sporulation-specific sigma factors (Losick \& Stragier, 1992; Errington, 1993; Table 1). The putative autolysins involved in germination are expressed during sporulation, since they are activated during germination before RNA and protein synthesis are restored.

The post-translational control of autolysin activity is more difficult to understand. B. subtilis cell walls contain a potentially lethal amount of autolytic activity throughout growth and must control this activity to prevent committing suicide by the action of their own enzymes. Although there has been much speculation about the mechanism of such control, there is still little hard evidence. Proposed mechanisms of autolysin control have included a number of possible inhomogeneities in the peptidoglycan substrate, particularly substrate conformation (Koch et al., 1985), covalent modification of the substrate (Clarke, 1993), distribution of secondary polymers (Rogers et al., 1980; Fischer et al., 1981) and the wall ionic environment (Cheung \& Freese, 1985). 
Observations that cell-wall autolysis is enhanced by depolarizing agents has led to proposals that autolysins may be controlled by the proton-motive force (Jolliffe $e t$ al., 1981; Kemper et al., 1993). Any of these effects, or combinations of them, could modulate the susceptibility of different regions of the cell wall to a number of autolysins, thus explaining the existence of several enzymes during vegetative growth that have different bond specificities but are all, more or less, involved in the same diverse processes.

The role of substrate conformation in determining autolysin activity is demonstrated by the GSLEs, which hydrolyse stressed, intact cortex, but not the same material from mechanically broken spores. One of the clearest examples of the role of covalent modification of peptidoglycan in determining autolysin activity is the muramic $\delta$-lactam of cortical peptidoglycan, which appears to be the feature of the cortex that makes it sensitive to the germination autolysins, allowing its selective removal without digestion of the primordial cell wall (Atrih et al., 1996; Popham et al., 1996a). However, the $\delta$-lactam cannot be the only feature of cortex that targets it for specific autolytic attack, because a $41 \mathrm{kDa}$ sporulation-specific autolysin, which hydrolyses cortex but not vegetative cell walls, is active even against cortex from the cwlD mutant (Smith \& Foster, 1997).

Differential control of different teichoic acid genes with differing cell division rates suggests that the teichoic acid (one of the major anionic polymers) may have a different structure in the septa than in the cylindrical parts of the wall (Mauël et al., 1995). For instance, an uneven distribution of negative charge over the cell wall was observed by preferential binding of positively charged cytochrome $c$ to the cylindrical regions rather than the poles (Wecke et al., 1997). If the primarily positively charged major autolysins were distributed similarly, this would explain the observed higher rate of wall turnover at the cylinders than the poles (Clarke-Sturman et al., 1989). Accelerated cell autolysis in a mutant with more negatively charged secondary polymers is consistent with this theory (Wecke et al., 1997). The observed de$\mathrm{N}$-acetylation of certain glucosamine residues in vegetative peptidoglycan also offers a mechanism for autolysin control (Atrih et al., 1999). Differential binding of autolysins, via their varied cell-wall-binding domains, to different parts of the cell surface may allow exquisite control of their sites and extent of action. Specific binding of the major S. aureus autolysin Atl around the plane of cell division has already been observed (Sugai et al., 1995). It seems unlikely that the major autolysins, which appear to act at numerous sites around the cell wall, are highly localized, but as yet uncharacterized minor enzymes with specialized functions may well be. Protein-protein interaction may also mediate the localization and control of autolysin activity. For instance, the modifier protein LytB, which enhances the in vitro activity of the major vegetative amidase LytC (Lazarevic et al., 1992), may be one of a number of factors involved in controlling autolytic activity in vivo.
Although the nature of the control mechanisms that cease upon cell death remain largely unknown, the major autolysins involved in post-mortem cell autolysis have been identified. The amidase LytC and the putative endopeptidase LytE have roles in cell-wall lysis after exposure of the culture to the metabolic poison sodium azide. No role for the major vegetative glucosaminidase LytD during cell lysis has been found (Blackman et al., 1998; Margot et al., 1994, 1998; Margot \& Karamata, 1992). Both LytC and LytD have mutually compensatory roles in lysis after exposure to the $\beta$-lactam antibiotic cloxacillin, although neither is required for cloxacillininduced cell death (Blackman et al., 1998).

\section{Prophage lytic enzymes}

The B. subtilis chromosome contains at least eight presumptive prophages or remnants thereof, identifiable by their prophage-related genes and high $\mathrm{A}+\mathrm{T}$ content relative to the bulk of the chromosome (Kunst et al., 1997). Lysogenic phages usually encode peptidoglycan hydrolases, known as lytic enzymes, to lyse the host cell wall and liberate the phage particles after replication. Access of lytic enzymes to their substrate also generally requires other gene products, including transmembrane holins (Krogh et al., 1998). Three peptidoglycan hydrolases in the XlyA amidase family, $x l y A$, yom C (blyA) and $c w l A$, are within the identified prophages PBSX, SP $\beta$ and skin, respectively, and appear to be phage lytic enzymes (Table 1). PBSX and SP $\beta$ remain lysogenic (Longchamp et al., 1994; Regamey \& Karamata, 1998), whilst skin has curiously become part of the sporulationcontrol apparatus. It interrupts the $\operatorname{sig} K$ gene, which encodes the mother-cell-specific late-sporulation sigma factor $\sigma^{\mathrm{K}}$. Excision of skin from the mother-cell chromosome by site-specific recombination $3 \mathrm{~h}$ after the onset of sporulation is necessary for $\sigma^{\mathrm{K}}$ expression and hence for successful completion of sporulation (Losick \& Stragier, 1992). CwlA, the amidase of the XlyA family encoded within skin (Takemaru et al., 1995), is an active peptidoglycan hydrolase (Kuroda \& Sekiguchi, 1990; Foster, 1991, 1993). skin may have been a temperate phage that inserted into the chromosome within $\operatorname{sig} K$. It has evolved to avoid blocking sporulation by its nonlytic excision from the mother-cell chromosome. This permits sporulation and ensures transmission of the 'prophage' via the endospore. cwlA and associated phage genes could persist because skin remains extant, or was so until relatively recently. CwlA could also be part of a mechanism to perpetuate skin within the host. skin persists in the host chromosome because it is excised only in the mother cell, which is committed to die at the end of sporulation, so no cell lacking skin is naturally propagated (Losick \& Stragier, 1992).

YomI, which has both Slt 70- and lysostaphin-like domains, is found within $\mathrm{SP} \beta$ and so may function in $\mathrm{SP} \beta$ lysis in addition to YomC (BlyA). The gene encoding $\mathrm{YddH}$, a member of the DL-endopeptidase II family, resides within the presumptive prophage 2 and so may 
be or have been involved in its lysis of the cell. $y d h D$ and yocH appear to be phage-related amidase genes distant on the chromosome from identified prophages, which may encode autolysins that are controlled by the host. yqeE, which is near to but outside skin, could be another such gene. The existence of such genes implies exchange of peptidoglycan hydrolase genes between the host and its phages, a phenomenon that has also been described in pneumococci (Sheenan et al., 1997). xlyB, a putative amidase gene of the XlyB family, lies near to but outside PBSX. Induction of PBSX produces two lytic enzymes, a $32 \mathrm{kDa}$ enzyme that corresponds to XlyA and another of $34 \mathrm{kDa}$ (Longchamp et al., 1994), very similar in size to the $33.7 \mathrm{kDa}$ XlyB. This confirms that part of the PBSX genome is, to some extent, distributed around the chromosome (Longchamp et al., 1994).

\section{Conclusions and future prospects}

Previously, understanding of the autolysins of B. subtilis and the roles they perform was hampered by their multiplicity and redundancy of function. Publication of the genome sequence has enabled estimation of the entire autolysin complement of B. subtilis at the genetic level (Table 1). The discovery of some 22 uncharacterized potential autolysins is consistent with previous zymographic results, suggesting that a number of autolysin genes remained to be identified (Smith et al., 1996; Blackman et al., 1998; Smith \& Foster, 1997). It also confirms results from physiological and peptidoglycan-structure studies that additional autolysin genes existed. As described in the preceding sections, the use of multiple gene inactivations is beginning to allow the complex orchestra of highly redundant, multiple-function autolysins to be understood.

As more microbial genome sequences become available, it becomes clear that apparent redundancy of gene function is common among genes involved in a wide range of physiological processes. Significant differences in the phenotypes of genetically very similar autolysindeficient mutants observed in different laboratories underlines the conclusion that the precise roles of individual autolysins in particular processes is highly sensitive to growth conditions and genetic background. These observations are consistent with functional redundancy arising from a need to adapt to a wide range of growth conditions in the environment.

Among the autolysins of $B$. subtilis, functional redundancy is evident throughout the life cycle, but is more pronounced during vegetative growth than sporulation. During vegetative growth there are two orders of functional redundancy: individual processes can be performed by any one of a number of enzymes, and individual enzymes can be involved in a number of processes. During differentiation, on the other hand, functional redundancy is less extreme. Perhaps the autolytic processes of differentiation are less susceptible to, or better isolated from, the environment than those of vegetative growth.
The autolysins of B. subtilis are remarkable not only in their number but also in their variety. We have identified no fewer than 11 distinct families of autolysins and possible autolysins, and biochemical studies show that there are at least six different types of hydrolytic bond specificity involved in cell-wall metabolism. Indeed, only one of the proposed hydrolytic bond specificities (D-alanine-meso-diaminopimelate endopeptidase, see Fig. 1) has not been observed. During vegetative growth it is surprising that the process of cell separation, which involves the specific removal of part of the septal peptidoglycan, can be performed by enzymes with at least three different hydrolytic bond specificities. It appears that the total level of autolysin activity is what governs the probability of daughter-cell separation. The compensatory nature of the autolysins involved in this process as well as others can be explained by the effect of lack of a particular class of enzymes on substrate availability. Thus, having one enzyme missing may provide more substrate for another resident enzyme, which will therefore compensate for the absence of the first and so avoid any potential problem for the cell. Weak, though significant, primary-structure similarities among a number of different classes suggest that the three-dimensional structures and catalytic mechanisms of some of the families are interrelated, although such theories remain to be substantiated by determination of the three-dimensional structure of bacillary autolysins.

It is intriguing that autolysins essential for vegetative growth of $B$. subtilis have not been identified. It is difficult to conceive how cell growth could be achieved without selected disconnection of covalent bonds within the peptidoglycan to permit cell-wall expansion, but the autolysins involved in this essential process have so far proved elusive. During cell elongation, maybe minor autolysins hydrolyse relatively few bonds, but create sites suitable for the action of the major autolysins. During cell growth, the former activity may correspond to the essential autolytic events essential for cell growth and the latter to the inessential wall-turnover-related autolysin activity. It is possible that enzyme activity is not involved or is inessential, and that the necessary breakage of bonds can occur by mechanical stress from the expanding cytoplasm (Archibald et al., 1993). More likely, however, is that the autolysins required in this carefully regulated process have not yet been identified.

The control of autolysin activity remains a mystery, and is one that seems difficult to solve by in vitro studies with isolated cell walls, when most autolysins have apparently run-away activity. One way forward is to isolate mutants that interfere with autolytic activity, thus defining what properties of the cell-wall environment are important. In this manner, study of a strain with cortical peptidoglycan lacking the muramic $\delta$-lactam structure has already identified the $\delta$-lactam as necessary for targeting the cortex for hydrolysis during germination (Atrih et al., 1996, 1998; Popham et al., 1996a).

We propose that the molecular origin of autolysin specificity, post-translational control of autolysin ac- 
tivity and characterization of the roles, if any, of autolysins in cell expansion are the major current questions that remain to be answered in the study of these important enzymes. A combined approach, using multiple gene inactivations, morphological and physiological studies, together with analysis of peptidoglycan fine structure, has already begun to unravel the molecular functions of the plethora of autolysins in $B$. subtilis. We suggest that continued application of similar technology may reveal every autolysin involved in each autolysin-requiring process. Together with parallel studies of the mechanism of peptidoglycan synthesis, a thorough understanding of the molecular origin of cellwall dynamics in B. subtilis now seems feasible.

\section{Acknowledgements}

We would like to thank Dimitri Karamata and Junichi Sekiguchi for helpful discussions, and the BBSRC and the Royal Society for funding the research.

\section{References}

Altschul, S. F., Madden, T. L., Schaeffer, A. A., Zhang, J., Zhang, Z., Miller, W. \& Lipman, D. J. (1991). Gapped BLAST and PSIBLAST: a new generation of protein database search programs. Nucleic Acids Res 25, 3389-3402.

Archibald, A. R., Hancock, I. C. \& Harwood, C. R. (1993). Cell wall structure, synthesis, and turnover. In Bacillus subtilis and other Gram-positive Bacteria, pp. 381-410. Edited by J. A. Hoch \& R. Losick. Washington, DC: American Society for Microbiology.

Atrih, A. \& Foster, S. J. (1999). The role of peptidoglycan structure and structural dynamics during dormancy and germination. Antonie Leeuwenhoek 75, 299-307.

Atrih, A., Zöllner, P., Allmaier, G. \& Foster, S. J. (1996). Structural analysis of Bacillus subtilis 168 endospore peptidoglycan and its role during differentiation. J Bacteriol 178, 6173-6183.

Atrih, A., Zöllner, P., Allmaier, G., Williamson, M. P. \& Foster, S. J. (1998). Peptidoglycan structural dynamics during germination of Bacillus subtilis 168 endospores. J Bacteriol 180, 4603-4612.

Atrih, A., Bacher, G., Allmaier, G., Williamson, M. P. \& Foster, S. J. (1999). Analysis of peptidoglycan structure from vegetative cells of Bacillus subtilis 168 and the role of PBP 5 in its maturation. J Bacteriol 181, 3956-3968.

Baba, T. \& Schneewind, O. (1996). Target cell specificity of a bacteriocin molecule: a C-terminal signal directs lysostaphin to the cell wall of Staphylococcus aureus. EMBO J 15, 4789-4797.

Baba, T. \& Schneewind, O. (1998). Targeting of murolytic enzymes to the cell-division site of Gram-positive bacteria : repeat domains direct autolysin to the equatorial surface ring of Staphylococcus aureus. EMBO J 17, 4639-4646.

Blackman, S. A. (1998). The role of autolysins during vegetative growth of Bacillus subtilis 168 . PhD thesis, University of Sheffield.

Blackman, S. A., Smith, T. J. \& Foster, S. J. (1998). The role of autolysins during vegetative growth of Bacillus subtilis 168. Microbiology 144, 73-82.

Boland, F. M., Atrih, A., Chirakkal, H., Foster, S. J. \& Moir, A. (2000). Complete spore-cortex hydrolysis during germination of Bacillus subtilis 168 requires SleB and YpeB. Microbiology 146, 57-64.

Braun, L., Dramsi, S., Dehoux, P., Bierne, H., Lindahl, G. \& Cossart,
P. (1997). InlB: an invasion protein of Listeria monocytogenes with a novel type of surface association. Mol Microbiol 25, 285-294.

Brunskill, E. W. \& Bayles, K. W. (1996). Identification of LytSRregulated genes from Staphylococcus aureus. J Bacteriol 178, 5810-5812.

Chen, Y., Miyata, S., Makino, S. \& Moriyama, R. (1997). Molecular characterization of a germination-specific muramidase from Clostridium perfringens S40 spores and nucleotide sequence of the corresponding gene. J Bacteriol 179, 3181-3187.

Cheung, H. Y. \& Freese, E. (1985). Monovalent cations enable cellwall turnover of the turnover-deficient lyt-15 mutant of Bacillus subtilis. J Bacteriol 161, 1222-1225.

Clarke, A. J. (1993). Extent of peptidoglycan $O$-acetylation in the tribe Proteae. J Bacteriol 175, 4550-4553.

Clarke-Sturman, A. J., Archibald, A. R., Hancock, I. C., Harwood, C. R., Merad, T. \& Hobot, J. A. (1989). Cell wall assembly in Bacillus subtilis: partial conversion of polar wall material and the effect of growth conditions on the pattern of incorporation of new material at the polar caps. J Gen Microbiol 135, 657-665.

Dijkstra, A. J. \& Keck, W. (1996). Peptidoglycan as a barrier to trans-envelope transport. J Bacteriol 178, 5555-5562.

Doi, R. H. (1989). Sporulation and germination. In Bacillus, pp. 169-215. Edited by C. R. Harwood. London: Plenum.

Errington, J. (1993). Bacillus subtilis sporulation: regulation of gene expression and control of morphogenesis. Microbiol Rev 57, $1-33$.

Fan, D. P. \& Beckman, M. M. (1971). Mutants of Bacillus subtilis demonstrating the requirement of lysis for growth. J Bacteriol 105, 629-636.

Fischer, W., Rosel, P. \& Koch, H. U. (1981). Effect of alanine ester substitution and other structural features of lipoteichoic acid on their inhibitory activity against autolysins of Staphylococcus aureus. J Bacteriol 146, 467-475.

Foster, S. J. (1991). Cloning, expression, sequence analysis and biochemical characterization of an autolytic amidase of Bacillus subtilis 168 trpC2. J Gen Microbiol 137, 1987-1998.

Foster, S. J. (1992). Analysis of the autolysins of Bacillus subtilis 168 during vegetative growth and differentiation by using renaturing polyacrylamide gel electrophoresis. J Bacteriol 174, 464-470.

Foster, S. J. (1993). Analysis of Bacillus subtilis 168 prophageassociated lytic enzymes: identification and characterization of CWLA-related prophage proteins. J Gen Microbiol 139, 3177-3184.

Foster, S. J. (1994). The role and regulation of cell wall structural dynamics during differentiation of endospore-forming bacteria. $J$ Appl Bacteriol 76, S25-S39.

Foster, S. J. (1995). Molecular characterization and functional analysis of the major autolysin of Staphylococcus aureus 8325/4. J Bacteriol 177, 5723-5725.

Foster, S. J. \& Johnstone, K. (1990). Pulling the trigger - the mechanism of bacterial spore germination. Mol Microbiol 4, 137-141.

Ghuysen, J.-M. (1991). Serine $\beta$-lactamases and penicillin-binding proteins. Annu Rev Microbiol 45, 37-67.

Ghuysen, J.-M., Tipper, D. J. \& Strominger, J. L. (1966). Enzymes that degrade bacterial cell walls. Methods Enzymol 8, 685-699.

Ghuysen, J.-M., Lamotte-Brasseur, J., Joris, B. \& Shockman, G. D. (1994). Binding site-shaped repeated sequences of bacterial wall peptidoglycan hydrolases. FEBS Lett 342, 23-28. 
Graham, L. L. \& Beveridge, T. J. (1994). Structural differentiation of the Bacillus subtilis 168 cell wall. J Bacteriol 176, 1413-1423.

Helmann, J. D., Marquez, L. M. \& Chamberlin, M. J. (1988). Cloning, sequencing and disruption of the Bacillus subtilis $\sigma^{28}$ gene. J Bacteriol 170, 1568-1574.

Herbold, D. R. \& Glaser, L. (1975). Bacillus subtilis N-acetylmuramic acid L-alanine amidase. J Biol Chem 250, 1676-1682.

Höltje, J. V., Mirelman, D., Sharon, N. \& Schwartz, U. (1975).

Novel type of murein transglycosylase in Escherichia coli. J Bacteriol 124, 1067-1076.

Hourdou, M.-L., Duez, C., Joris, B., Vacheron, M.-J., Guinand, M., Michel, G. \& Ghuysen, J.-M. (1992). Cloning and nucleotide sequence of the gene encoding the $\gamma$-D-glutamyl-L-diamino acid endopeptidase II of Bacillus sphaericus. FEMS Microbiol Lett 91, 165-170.

Hourdou, M.-L., Guinand, M., Vacheron, M.-J. \& 7 other authors (1993). Characterization of the sporulation-related $\gamma$-D-glutamyl(L)meso-diaminopimelic-acid-hydrolysing peptidase I of Bacillus sphaericus ACTC 9602 as a member of the metallo(zinc) carboxypeptidase A family. Biochem J 292, 563-570.

Illing, N. \& Errington, J. (1991). Genetic regulation of morphogenesis in Bacillus subtilis: roles of $\sigma^{\mathrm{E}}$ and $\sigma^{\mathrm{F}}$ in prespore engulfment. J Bacteriol 173, 3159-3169.

Ishikawa, S., Hara, Y., Ohnishi, R. \& Sekiguchi, J. (1998a). Regulation of a new cell wall hydrolase gene, $c w l F$, which affects cell separation in Bacillus subtilis. J Bacteriol 180, 2549-2555.

Ishikawa, S., Yamane, K. \& Sekiguchi, J. (1998b). Regulation and characterization of a newly deduced cell wall hydrolase gene $(c w l J)$ which affects germination of Bacillus subtilis spores. J Bacteriol 180, 1375-1380.

Jolliffe, L. K., Doyle, R. J. \& Streips, U. N. (1981). The energised membrane and cellular autolysis in Bacillus subtilis. Cell 25, 753-763.

Joris, B., Englebert, S., Chu, C.-P., Kariyama, R., Daneo-Moore, L., Shockman, G. D. \& Ghuysen, J.-M. (1992). Modular design of the Enterococcus hirae muramidase 2 and Streptococcus faecalis autolysin. FEMS Microbiol Lett 91, 257-264.

Kemper, M. A., Urrutia, M. M., Beveridge, T. J., Koch, A. L. \& Doyle, R. J. (1993). Proton motive force may regulate cell-wallassociated enzymes of Bacillus subtilis. J Bacteriol 175, 5690-5696.

Koch, A. L. (1995). Bacterial Growth and Form. New York: Chapman \& Hall.

Koch, A. L., Kirchner, G., Doyle, R. J. \& Streips, U. N. (1985). How does Bacillus split its septum right down the middle? Ann Inst Pasteur Microbiol 136, 91-98.

Krogh, S., Jorgensen, S. T. \& Devine, K. M. (1998). Lysis genes of the Bacillus subtilis defective prophage PBSX. J Bacteriol 180, 2110-2117.

Kuchler, K. (1993). Unusual routes of protein secretion: the easy way out. Trends Cell Biol 3, 421-426.

Kunst, F., Ogasawara, N., Moszer, I. \& 148 other authors (1997). The complete genome sequence of the Gram-positive bacterium Bacillus subtilis. Nature 390, 249-256.

Kuroda, A. \& Sekiguchi, J. (1990). Cloning, sequencing and genetic mapping of a Bacillus subtilis cell wall hydrolase gene. J Gen Microbiol 136, 2209-2216.

Kuroda, A. \& Sekiguchi, J. (1991). Molecular cloning and sequencing of a major Bacillus subtilis autolysin gene. J Bacteriol 173, 7304-7312.

Kuroda, A. \& Sekiguchi, J. (1993). High-level transcription of the major Bacillus subtilis autolysin operon depends on expression of the sigma D gene and is affected by a $\sin (f l a D)$ mutation. $J$ Bacteriol 175, 795-801.

Kuroda, A., Rashid, M. H. \& Sekiguchi, J. (1992). Molecular cloning and sequencing of the upstream region of the major Bacillus subtilis autolysin gene: a modifier protein exhibiting sequence homology to the major autolysin and the spoIID product. J Gen Microbiol 138, 1067-1076.

Kuroda, A., Asami, Y. \& Sekiguchi, J. (1993). Molecular cloning of a sporulation-specific cell wall hydrolase gene of Bacillus subtilis. J Bacteriol 175, 6260-6268.

Lazarevic, V., Margot, P., Soldo, B. \& Karamata, D. (1992). Sequencing and analysis of the Bacillus subtilis lytRABC divergon: a regulatory unit encompassing the structural genes of the $N$-acetylmuramoyl-L-alanine amidase and its modifier. J Gen Microbiol 138, 1949-1961.

Loessner, M. J., Wendlinger, G. \& Scherer, S. (1995). Heterogeneous endolysins in Listeria monocytogenes bacteriophages: a new class of enzymes and evidence for conserved holin genes within siphoviral lysis cassettes. Mol Microbiol 16, 1231-1241.

Londoño-Vallejo, J.-A., Fréhel, C. \& Stragier, P. (1997). spoIIQ, a forespore-expressed gene required for engulfment in Bacillus subtilis. Mol Microbiol 24, 29-39.

Longchamp, P. F., Mauël, C. \& Karamata, D. (1994). Lytic enzymes associated with defective prophages of Bacillus subtilis: sequencing and characterization of the region comprising the $\mathrm{N}$ acetylmuramoyl-L-alanine amidase gene of prophage PBSX. Microbiology 140, 1855-1867.

Losick, R. \& Stragier, P. (1992). Crisscross regulation of cell-typespecific gene expression during development in B. subtilis. Nature 355, 601-604.

McLaughlan, A. M. \& Foster, S. J. (1998). Molecular characterization of an autolytic amidase of Listeria monocytogenes EGD. Microbiology 144, 1359-1367.

Makino, S., Ito, N., Inoue, T., Miyata, S. \& Moriyama, R. (1994). A spore-lytic enzyme released from Bacillus cereus spores during germination. Microbiology 140, 1403-1410.

Margot, P. \& Karamata, D. (1992). Identification of the structural genes for $\mathrm{N}$-acetylmuramoyl-L-alanine amidase and its modifier in Bacillus subtilis 168: inactivation of these genes by insertional mutagenesis has no effect on growth or cell separation. Mol Gen Genet 232, 359-366.

Margot, P., Mauël, C. \& Karamata, D. (1994). The gene of the Nacetylglucosaminidase, a Bacillus subtilis 168 cell wall hydrolase not involved in vegetative cell autolysis. Mol Microbiol 12, 535-545.

Margot, P., Whalen, M., Gholamhoseinian, A., Piggot, P. \& Karamata, D. (1998). The lytE gene of Bacillus subtilis 168 encodes a cell wall hydrolase. J Bacteriol 180, 749-752.

Margot, P., Pagni, M. \& Karamata, D. (1999). Bacillus subtilis 168 gene $l y t F$ encodes a $\gamma$-D-glutamate-meso-diaminopimelate muropeptidase expressed by the alternative vegetative sigma factor, $\sigma^{\mathrm{D}}$. Microbiology 145, 57-65.

Mauël, C., Bauduret, A., Chervet, C., Beggah, S. \& Karamata, D. (1995). In Bacillus subtilis 168, teichoic acid of the cross-wall may be different from that of the cylinder: a hypothesis based on transcriptional analysis of tag genes. Microbiology 141, 2379-2389.

Merad, T., Archibald, A. R., Hancock, I. C., Harwood, C. R. \& Hobot, J. A. (1989). Cell wall assembly in Bacillus subtilis: visualisation of old and new wall material by electron microscopic examination of samples stained selectively for teichoic acid and teichuronic acid. J Gen Microbiol 135, 645-655. 
Merchante, R., Pooley, H. M. \& Karamata, D. (1995). A periplasm in Bacillus subtilis. J Bacteriol 177, 6176-6183.

Moriyama, R., Hattori, A., Miyata, S., Kudoh, S. \& Makino, S. (1996). A gene (sleB) encoding a spore cortex-lytic enzyme from Bacillus subtilis and response of the enzyme to L-alanine mediated germination. J Bacteriol 178, 6059-6063.

Nugroho, F. A., Yamamoto, H., Kobayashi, Y. \& Sekiguchi, J. (1999). Characterization of a new sigma-K-dependent peptidoglycan hydrolase gene that plays a role in Bacillus subtilis mother cell lysis. J Bacteriol 181, 6230-6237.

Ohnishi, R., Ishikawa, S. \& Sekiguchi, J. (1999). Peptidoglycan hydrolase LytF plays a role in cell separation with CwlF during vegetative growth of Bacillus subtilis. J Bacteriol 181, 3178-3184.

Oshida, T., Sugai, M., Komatsuzawa, H., Hong, Y. M., Suginaka, H. \& Tomasz, A. (1995). A Staphylococcus aureus autolysin that has an $\mathrm{N}$-acetylmuramoyl-L-alanine amidase domain and an endo- $\beta$ - $N$-acetylglucosaminidase domain: cloning, sequence analysis, and characterization. Proc Natl Acad Sci USA 92, 285-289.

Pooley, H. M. (1976). Layered distribution, according to age, within the cell wall of Bacillus subtilis. J Bacteriol 125, 1139-1147.

Pooley, H. \& Karamata, D. (1984a). Flagellation and the control of autolysins in Bacillus subtilis. In Microbial Cell Wall Synthesis and Autolysis, pp. 13-19. Edited by C. Nombela. Amsterdam: Elsevier.

Pooley, H. \& Karamata, D. (1984b). Genetic analysis of autolysindeficient and flagellaless mutants of Bacillus subtilis. J Bacteriol 160, 1123-1129.

Popham, D. L., Helin, J., Costello, C. E. \& Setlow, P. (1996a). Muramic lactam in peptidoglycan of Bacillus subtilis spores is required for spore outgrowth but not spore germination. Proc Natl Acad Sci USA 93, 15405-15410.

Popham, D. L., Helin, J., Costello, C. E. \& Setlow, P. (1996b). Analysis of the peptidoglycan structure of Bacillus subtilis endospores. J Bacteriol 178, 6451-6458.

Popham, D. L., Gilmore, M. E. \& Setlow, P. (1999). Roles of lowmolecular-weight penicillin-binding proteins in Bacillus subtilis spore peptidoglycan synthesis and spore properties. J Bacteriol 181, 126-132.

Rashid, M. H. \& Sekiguchi, J. (1996). flaD $(\sin R)$ mutations affect SigD-dependent functions at multiple points in Bacillus subtilis. J Bacteriol 178, 6640-6643.

Rashid, M. H., Sato, N. \& Sekiguchi, J. (1995a). Analysis of the minor autolysins of Bacillus subtilis during vegetative growth by zymography. FEMS Microbiol Lett 132, 131-137.

Rashid, M. H., Mori, M. \& Sekiguchi, J. (1995b). Glucosaminidase of Bacillus subtilis: cloning, regulation, primary structure and biochemical characterisation. Microbiology 141, 2391-2404.

Recsei, P. A., Gruss, A. D. \& Novick, R. P. (1987). Cloning, sequence, and expression of the lysostaphin gene from Staphylococcus simulans. Proc Natl Acad Sci USA 84, 1127-1131.

Regamey, A. \& Karamata, D. (1998). The N-acetylmuramoyl-Lalanine amidase encoded by the Bacillus subtilis 168 prophage SP $\beta$. Microbiology 144, 885-893.

Rogers, H. J., Perkins, H. R. \& Ward, J. B. (1980). The bacterial autolysins. In Microbial Cell Walls and Membranes, pp. 191-214. London: Chapman \& Hall.

Rogers, H. J., Taylor, C., Rayter, S. \& Ward, J. B. (1984). Purification and properties of an autolytic endo- $\beta$ - $N$-glucosaminidase and the $\mathrm{N}$-acetylmuramyl-L-alanine amidase from Bacillus subtilis strain 168. J Gen Microbiol 130, 2395-2402.

Schindler, C. A. \& Schuhardt, V. T. (1964). Lysostaphin: a new bacteriolytic agent for the staphylococci. Proc Natl Acad Sci USA 51, 414-421.

Sekiguchi, J., Akeo, K., Yamamoto, H., Khasnov, F. K., Alonso, J. C. \& Kuroda, A. (1995). Nucleotide sequence and regulation of a new putative cell wall hydrolase gene, cwlD, which affects germination in Bacillus subtilis. J Bacteriol 177, 5582-5589.

Sheenan, M. M., García, J. L., López, R. \& García, P. (1997). The lytic enzyme of the pneumococcal phage Dp-1: a chimeric lysin of intergeneric origin. Mol Microbiol 25, 717-725.

Shockman, G. D. \& Höltje, J.-V. (1994). Microbial peptidoglycan (murein) hydrolases. In Bacterial Cell Wall, pp. 131-166. Edited by J.-M. Ghuysen \& R. Hakenbeck. Amsterdam: Elsevier.

Smith, T. J. \& Foster, S. J. (1995). Characterization of the involvement of two compensatory autolysins in mother cell lysis during sporulation of Bacillus subtilis 168. J Bacteriol 177, 3855-3862.

Smith, T. J. \& Foster, S. J. (1997). Autolysins during sporulation of Bacillus subtilis 168. FEMS Microbiol Lett 157, 141-147.

Smith, T. J., Blackman, S. A. \& Foster, S. J. (1996). Peptidoglycan hydrolases of Bacillus subtilis 168. Microb Drug Resist 2, 113-118.

Sugai, M., Komatsuzawa, H., Akiyama, T., Hong, Y. M., Oshida, T., Miyake, Y., Yamaguchi, T. \& Suginaka, H. (1995). Identification of endo- $\beta$ - $N$-acetylglucosaminidase and $N$-acetylmuramyl-L-alanine amidase as cluster-dispersing enzymes in Staphylococcus aureus. J Bacteriol 177, 1491-1496.

Takemaru, K., Mizuno, M., Sato, T., Takeuchi, M. \& Kobayashi, Y. (1995). Complete nucleotide sequence of a skin element excised by DNA rearrangement during sporulation in Bacillus subtilis. Microbiology 141, 323-327.

Thunnissen, A.-M. W. H., Dijkstra, A. J., Kalk, K. H., Rozeboom, H. J., Engel, H., Keck, W. \& Dijkstra, B. W. (1994). Doughnutshaped structure of a bacterial muramidase revealed by X-ray crystallography. Nature 367, 750-753.

Tipper, D. J. \& Gauthier, J. J. (1972). Structure of the bacterial endospore. In Spores V, pp. 3-12. Edited by H. O. Halvorson, R. Hanson \& L. L. Campbell. Washington, DC: American Society for Microbiology.

Tipper, D. J. \& Linnett, P. E. (1976). Distribution of peptidoglycan synthetase activities between sporangia and forespores in sporulating cells of Bacillus sphaericus. J Bacteriol 126, 213-221.

Warth, A. D. (1978). Molecular structure of the bacterial spore. Adv Microbiol Physiol 17, 1-47.

Wecke, J., Madela, K. \& Fischer, W. (1997). The absence of Dalanine from lipoteichoic acid and wall teichoic acid alters surface charge, enhances autolysis and increases susceptibility to methicillin in Bacillus subtilis. Microbiology 143, 2953-2960.

Wuenscher, M. D., Köler, S., Bubert, A., Gerike, U. \& Goebel, W. (1993). The iap gene of Listeria monocytogenes is essential for cell viability, and its gene product, p60, has autolytic activity. $J$ Bacteriol 175, 3409-3501. 